\title{
Phase II study of pazopanib monotherapy in metastatic gastroenteropancreatic neuroendocrine tumours
}

\author{
H K Ahn ${ }^{1,2,6}$, J Y Choi ${ }^{3,6}, \mathrm{~K}-\mathrm{M} \mathrm{Kim}{ }^{4}, \mathrm{H} \mathrm{Kim}^{5}$, S-H Choi ${ }^{5}$, S H Park ${ }^{1}$, J O Park ${ }^{1}, \mathrm{H}$ Y Lim ${ }^{1}$, W K Kang ${ }^{1}, \mathrm{~J} \mathrm{Lee}^{*, 1}$ \\ and Y S Park ${ }^{*}, 1$ \\ ${ }^{1}$ Division of Hematology-Oncology, Department of Medicine, Samsung Medical Center, Sungkyunkwan University School of \\ Medicine, Seoul, Korea; ${ }^{2}$ Department of Internal Medicine, Gachon University Gil Medical Center, Incheon, Korea; ${ }^{3}$ Department of \\ Nuclear Medicine, Samsung Medical Center, Sungkyunkwan University School of Medicine, Seoul, Korea; ${ }^{4}$ Department of \\ Pathology, Samsung Medical Center, Sungkyunkwan University School of Medicine, Seoul, Korea and ${ }^{5}$ Department of Surgery, \\ Samsung Medical Center, Sungkyunkwan University School of Medicine, Seoul, Korea
}

Background: Treatment options for patients with metastatic gastroenteropancreatic neuroendocrine tumours (GEP NETs) are still limited. We investigated the antitumour activity and safety profile of pazopanib - a multitarget drug with anti-angiogenic activity in patients with metastatic GEP NETs.

Methods: This was a nonrandomised, open-labeled, single-center phase II study. Pazopanib was orally administered at a dose of $800 \mathrm{mg}$ daily continuously with a 28-day cycle. The primary end point was an objective response rate according to Response Evaluation Criteria in Solid Tumors (RECIST). The secondary end points were progression-free survival (PFS), overall survival (OS) and safety. An independent review of objective response was planned. The trial is registered with ClinicalTrials.gov, NCT number 01099540. Correlative biomarker analyses were performed.

Results: Between April 2010 and February 2012, a total of 37 patients were enrolled. Thirty-two percent of the enrolled patients had pancreatic primary and $22 \%$ of the patients had colorectal primary NETs. This phase II study demonstrated an objective response rate of $18.9 \%$ ( 7 of the $37,95 \% \mathrm{Cl} 8.0-35.2$ ) and a disease control rate (CR + confirmed PR + stable disease) of $75.7 \%$ (28 of the 37, 95\% Cl, 58.8-88.2) in metastatic GEP NETs. The independent review demonstrated a higher overall response rate of $24.3 \%$ (95\% Cl, 11.8-41.2\%) with nine confirmed PRs.

Conclusion: Pazopanib showed a comparable efficacy to other targeted agents not only in pancreatic NETs but also in NETs originating from gastrointestinal (Gl) tract.

Gastroenteropancreatic neuroendocrine tumours (GEP NETs) are a heterogeneous group of malignancies derived from neuroendocrine cell compartments in various organs. Data from recent population-based studies demonstrate a significant increase in the reported incidence of NETs over time and the incidence ranges from 2.5 to 5 cases per 100000 in Caucasian population. (Hemminki and Li, 2001; Lepage et al, 2007; Hauso et al, 2008; Yao et al, 2008a) On the basis of a survey of 13175 carcinoids by the SEER Program from 1973 to 1999, the greatest incidence of carcinoids was in the gastrointestinal (GI) tract (67.5\%) and the bronchopulmonary system (25.3\%) (Modlin et al, 2003). Within the GI tract, most carcinoid tumours occurred in the small intestine (41.8\%), rectum (27.4\%) and stomach (8.7\%) (Modlin et al, 2003). According to several epidemiologic studies including ours, (Lim et al, 2011) there is a geographic variation in the anatomic origin of GEP NETs. In unresectable or metastatic GEP

*Correspondence: Dr YS Park; E-mail: pys27hmo@skku.edu or Dr J Lee; E-mail: jyunlee@skku.edu
${ }^{6}$ These authors contributed equally to this work.

Received 28 March 2013; revised 12 June 2013; accepted 23 July 2013; published online 29 August 2013

(c) 2013 Cancer Research UK. All rights reserved 0007-0920/13 
NETs, systemic treatment options have been severely limited (Naraev et al, 2012).

Gastroenteropancreatic neuroendocrine tumours are known as hypervascular tumours with increased expressions of vascular endothelial growth factor (VEGF) and VEGF receptors (VEGFRs) (Terris et al, 1998), which are associated with poor prognosis. The presence of VEGFR-2 was detected in $\sim 48 \%$ of carcinoid tumours, with the highest expression in foregut and hindgut carcinoids. A modest clinical activity with bevacizumab, a monoclonal antibody targeting VEGF, has been observed in advanced neuroendocrine tumours in phase II studies. A randomised phase II study that compared bevacizumab with interferon alpha treatment has demonstrated a response rate of $18 \%$ with a trend towards longer progression-free survival (PFS) in bevacizumab arm (Yao et al, 2008b). Most recently, a phase II study on bevacizumab and temozolomide combination treatment showed a response rate of 15\% and a median PFS of 11.0 months in 34 GEP NET patients including poorly differentiated (G3) NET (Chan et al, 2012). In pancreatic NET, continuous administration of sunitinib was compared with placebo in a phase III trial of 171 patients suffering from pancreatic NETs, and median PFS was significantly prolonged in the sunitinib arm (11.4 vs 5.5 months) (Raymond et al, 2011). On the basis of these data, sunitinib was approved in the United States for the treatment of progressive, welldifferentiated pancreatic NET patients.

Pazopanib (GW786034; GlaxoSmithKline, Stevenage, UK) is a novel oral multitargeted tyrosine kinase inhibitor with a wide range of activities that are mediated through VEGFR types 1,2 and 3 , platelet-derived growth factor receptors $\alpha$ and $\beta$, and stem-cell factor receptor (c-Kit) (Kumar et al, 2009; Hamberg et al, 2010). In a phase I pazopanib trial with 63 patients, one patient with neuroendocrine tumour (primary not specified) demonstrated a partial response (PR) to pazopanib (Hurwitz et al, 2009). In a preliminary report on phase II pazopanib for pancreatic NETs, the response rate of $17 \%$ was reported (Phan et al, 2010).

In contrast to pancreatic NETs, there are very limited data on the efficacy of tyrosine kinase inhibitors in non-pancreatic NETs. Given the high incidence of non-pancreatic NETs, such as those originating from colorectum and small intestine, the antitumour efficacy of molecularly targeted agents should be tested in nonpancreatic NET patients, who could potentially benefit from TKIs. Hence, we designed a phase 2 study of pazopanib in patients with metastatic GEP NETs to assess the safety and efficacy of pazopanib.

\section{MATERIALS AND METHODS}

Patients. Eligibility criterion included a histologically confirmed diagnosis of advanced (metastatic) GEP NET, which is not amenable to locoregional therapies including transarterial embolisation or radiofrequency ablation. Histological grade was categorised as follows: carcinoid tumour or well-differentiated NET was classified as G1 tumour; atypical carcinoid or welldifferentiated neuroendocrine carcinoma was classified as G2 tumour and poorly differentiated neuroendocrine carcinoma was classified as G3 tumour (Klimstra et al, 2010). In patients with G3 NET, one previous cytotoxic chemotherapy regimen was required to enter the trial. Tumours originating from GI tract or unknown primary site, or nonfunctioning pancreatic islet cell tumour was included. The complete lists of inclusion and exclusion criteria are reported in the protocol. Written informed consent was obtained from all patients. The present study was an investigator-initiated, single-centre study. This study was approved by the Institutional Review Board at the Samsung Medical Center.
Study design. This was a non-randomised, open-labelled, singlecentre phase II study (NCT number 0109954). The primary end point was an objective response rate according to the Response Evaluation Criteria in Solid Tumor (RECIST) version 1.1. The secondary end points were PFS, overall survival (OS) and safety. Correlative biomarker analyses were preplanned in the protocol.

Study treatment. Pazopanib was orally administered at a dose of $800 \mathrm{mg}$ daily continuously with a 28-day cycle. When dose reduction was required, pazopanib was reduced by $200 \mathrm{mg}$. Treatment was discontinued when disease had progressed, when a participant experienced unacceptable adverse events, when a participant withdrew consent or when drug-related toxicity required treatment interruption for more than 21 days. Pazopanib was permanently discontinued for patients who developed grade 4 toxicities (except for patients with grade 4 anaemia, neutropaenia or thrombocytopaenia, in which cases toxicities were managed with treatment interruption and dose reduction), grade 3 haemorrhage, grade 3 hand-foot syndrome, grade 3 rash, arterial embolism, cerebrovascular accident, QTc $\geqslant 500 \mathrm{~ms}$ or pancreatitis of any grade.

Assessments. Tumour responses were assessed by contrastenhanced computed tomography scans of chest and abdomen every 4 weeks for the first 12 weeks of the study-drug administration and every 8 weeks thereafter. Before a status of complete response (CR) or $\mathrm{PR}$ was assigned, the tumour measurements were confirmed by another scan no less than, and as close as possible to, 4 weeks following initial documentation of an objective response. An independent radiological review was performed by a board-certified radiologist using RECIST 1.1. Positron-emission tomography (PET) scans using ${ }^{18} \mathrm{~F}$-fluorodeoxyglucose (FDG) at baseline were recommended in the protocol. Patients were observed until death or study closure. Toxicities were assessed according to the NCI CTCAE v4.0.

Correlative laboratory analysis. Serum CgA was assayed before commencement of the study drug. Pretreated archival tissue was collected and assayed for Ki-67 and $\mathrm{PHH} 3$ expression by immunohistochemistry. Immunohistochemistry was performed in $4 \mu \mathrm{m}$ sections of paraffin-embedded archival tissue on Leica BOND-MAX and BOND-III automated IHC staining systems (Leica Microsystems, Wetzlar, Germany). As a primary antibody, MIB1 (DAKO, Glostrup, Denmark; 1:300 dilution) was used for Ki-67 staining and 3H10 (Millipore, Bellerica, MA, USA; $1: 2000$ dilution) was used for PHH3. The staining of both Ki-67 and $\mathrm{PHH} 3$ was evaluated by counting positive cells, and the percentage of positive tumour cell nuclei was counted in at least 100 cells for each case (magnification $\times 400$, field size $0.18 \mathrm{~mm}^{2}$ ) in selected 'hot spot' areas.

Statistics. To test the null hypothesis of response rate of $5 \%$ and an alternative of $25 \%$ with a type I error rate of $5 \%$ and type 2 of $10 \%, 30$ patients were required. Considering a $15 \%$ drop-out rate, 35 patients were planned to be accrued. Progression-free survival and OS were estimated using the Kaplan-Meier method and compared by the log-rank test. The PFS was estimated from the date of the first administration of pazopanib to death, documented progression or the date of the last follow-up visit. The OS was defined as the time from the date of the first administration of pazopanib to death or the date of the last follow-up visit. All statistical analyses were performed using the SPSS software (IBM SPSS Statistics for Windows, Version 20.0; IBM Corp, Armonk, NY, USA). 


\section{RESULTS}

Patients and treatment outcome. Between April 2010 and February 2012, a total of 37 patients were enrolled. At the time of enrollment, 30 of the 37 patients had documented progressive diseases within 3 months and the other seven patients at the time of first diagnosis. Patient characteristics are shown in Table 1. Eight patients (22\%) had G1, 16 (43\%) had G2 and 13 (35\%) had G3 GEP NETs originating from different primary sites, with pancreatic site $(n=12)$ being the most common one followed by colorectal site $(n=8,22 \%)$. Other primary sites were stomach $(n=4)$, duodenum $(n=3)$, liver $(n=5)$ and gall bladder $(n=1)$; in four cases, primary sites were unknown. All patients had metastatic disease at the time of study treatment.

\section{Table 1. Baseline characteristics of the patients $(n=37)$}

\begin{tabular}{|c|c|}
\hline Characteristic & Number (\%) \\
\hline \multicolumn{2}{|l|}{ Age (years) } \\
\hline $\begin{array}{l}\text { Median } \\
\text { range }\end{array}$ & $\begin{array}{c}55 \\
19-71\end{array}$ \\
\hline \multicolumn{2}{|l|}{ Sex } \\
\hline $\begin{array}{l}\text { Male } \\
\text { Female }\end{array}$ & $\begin{array}{l}25(68) \\
12(32)\end{array}$ \\
\hline \multicolumn{2}{|l|}{ ECOG performance status } \\
\hline $\begin{array}{l}0 \\
1\end{array}$ & $\begin{array}{r}4(11) \\
33(89)\end{array}$ \\
\hline \multicolumn{2}{|l|}{ Histology } \\
\hline $\begin{array}{l}\text { Well-differentiated neuroendocrine tumour, G1 } \\
\text { Well-differentiated neuroendocrine carcinoma, G2 } \\
\text { Poorly differentiated neuroendocrine carcinoma, G3 }\end{array}$ & $\begin{array}{r}8(22) \\
16(43) \\
13(35)\end{array}$ \\
\hline \multicolumn{2}{|l|}{ Prior treatment } \\
\hline $\begin{array}{l}\text { Recurrence after curative surgery } \\
\text { Palliative surgery } \\
\text { Palliative radiotherapy } \\
\text { Palliative chemotherapy } \\
\text { None }\end{array}$ & $\begin{array}{c}5(14) \\
9(24) \\
3(8) \\
14(38) \\
19(51)\end{array}$ \\
\hline \multicolumn{2}{|l|}{ Primary site } \\
\hline $\begin{array}{l}\text { Pancreas } \\
\text { Colorectum } \\
\text { Stomach } \\
\text { Duodenum } \\
\text { Liver } \\
\text { Gall bladder } \\
\text { Unknown }\end{array}$ & $\begin{aligned} & 12(32) \\
8 & (22) \\
4 & (11) \\
3 & (8) \\
5 & (14) \\
1 & (3) \\
4 & (11)\end{aligned}$ \\
\hline \multicolumn{2}{|l|}{ Number of metastatic sites } \\
\hline $\begin{array}{l}1 \\
2 \\
\geqslant 3\end{array}$ & $\begin{array}{r}17(46) \\
13(35) \\
6(16) \\
\end{array}$ \\
\hline \multicolumn{2}{|l|}{ Metastatic sites } \\
\hline $\begin{array}{l}\text { Liver } \\
\text { Distant lymph nodes } \\
\text { Lung } \\
\text { Bone }\end{array}$ & $\begin{array}{l}32(89) \\
16(43) \\
6(16) \\
2(5)\end{array}$ \\
\hline Chromogranin level at baseline $(n=29)$ & $\mathrm{ng} \mathrm{ml}^{-1}$ \\
\hline Median, range & $110,30-800$ \\
\hline
\end{tabular}

Of the 37 patients enrolled on to the study, 3 patients were not assessable for treatment response. By an intent-to-treat analysis including all patients, an overall response rate of $18.9 \%$ was demonstrated (95\% CI, 8.0-35.2\%), with zero CR and seven PRs. Stable disease (SD) was achieved in 21 (56.8\%) patients. The overall disease-control rate $(\mathrm{CR}+\mathrm{PR}+\mathrm{SD})$ was $75.7 \%(95 \% \mathrm{CI}$, $58.8-88.2 \%$ ) (Table 2). Sixteen percent of the patients progressed to pazopanib. As shown in the waterfall plot (Figure 1A), tumour shrinkage of target lesions was observed in 22 patients (59.5\%) when compared with the baseline tumour measurement according to RECIST 1.1. In three patients, more prominent tumour volume reduction was noted (by $37 \%, 45 \%$, and $54 \%$, respectively),

\section{Table 2. Response according to RECIST (version 1.1) and survival} outcome

\begin{tabular}{|l|c|}
\hline Response & Number of patients (\%, 95 Cl) \\
\hline Complete response & $0(0 \%)$ \\
\hline Confirmed partial response & $7(18.9 \%, 8.0-35.2)$ \\
\hline Confirmed stable disease & $6(16 \%, 6.25-32.0)$ \\
\hline Progressive disease & $3(8.1 \%)$ \\
\hline Withdrawal without evaluation & $28(75.7 \%, 58.8-88.2)$ \\
\hline Disease control rate (CR+PR+ SD) & Abbreviations: $\mathrm{Cl}=$ confidence interval; RECIST= response evaluation criteria in solid \\
tumors
\end{tabular}
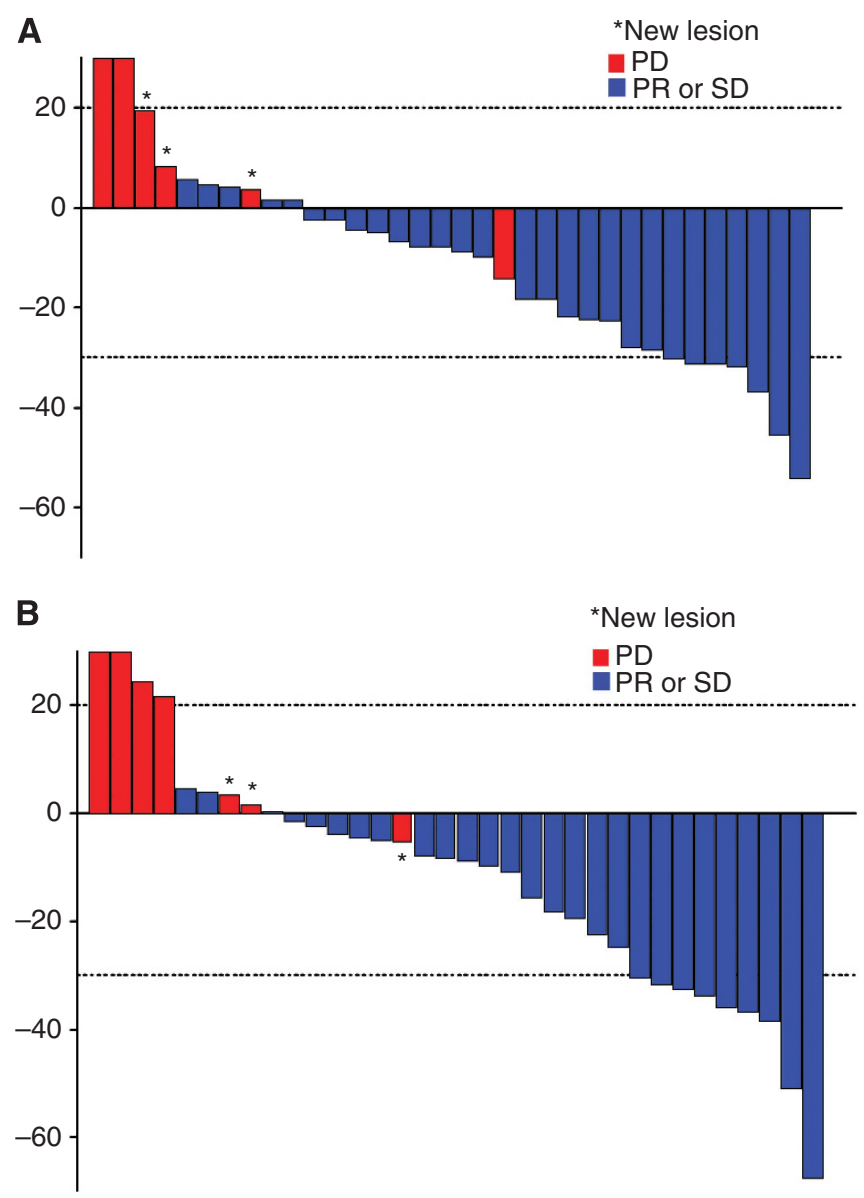

Figure 1. A waterfall plot demonstrating the maximum reduction in tumour size $(\mathbf{A})$ by site investigators and $(\mathbf{B})$ after independent review. 
A OS

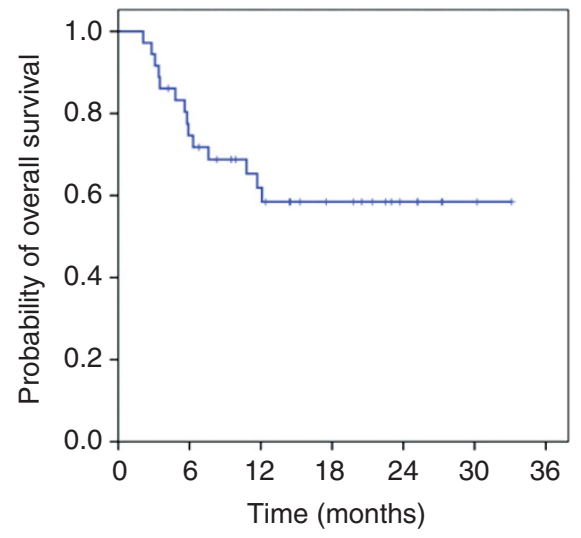

Figure 2. Survival curves (A) overall survival; (B) progression survival.

according to the RECIST criteria version 1.1. A separate independent review was performed by an expert radiologist who was blinded of the treatment response or treatment outcome (Figure 1B). The independent review demonstrated a higher overall response rate of $24.3 \%$ (95\% CI, $11.8-41.2 \%$ ), with nine confirmed PRs. A disease-control rate $(\mathrm{CR}+\mathrm{PR}+\mathrm{SD})$ from an independent review was $73 \%$ (95\% CI, 55.9-86.2\%). Hence, there was no significant difference in the overall response rate between investigators and an independent radiologist (18.9\% and $24.3 \%$, respectively). After a median follow-up duration of 31.2 months (range, 13.5-100 months), the median PFS was 9.1 months (95\% CI 4.9-13.3 months) (Figure 2). The median OS was not reached at the time of analysis.

Toxicity. The safety population included patients who were treated with at least one dose of the study drug. In total, 37 patients were evaluable for toxicities (Table 3). The most common grades 3 and 4 AEs were proteinuria (11\%), neutropaenia (8\%), hypertension (5\%), diarrhoea (5\%), anorexia (5\%), abdominal pain (5\%) and AST/ALT elevation (5\%). There was no treatment-related mortality.

Biomarker analysis. All biomarker analyses were preplanned. Baseline serum CgA level before the study treatment was measured in 29 patients. The median $\mathrm{CgA}$ value for this study population was $110 \mathrm{ng} \mathrm{ml}^{-1}$ (range, $30-800 \mathrm{ng} \mathrm{ml}^{-1}$ ). Patients with low CgA level $(<$ median $\mathrm{CgA}$ level) demonstrated a trend towards prolonged survival (median OS 11.7 months) $(P=0.080)$ (Figure $3 \mathrm{~A}$ ). Expression levels of Ki-67 and PHH3 were significantly correlated with statistical significance (Spearman's $R$ correlation coefficient $0.79, P<0.001)$. The survival according to the Ki-67 index and $\mathrm{PHH} 3$ is shown in Figure 3. Baseline FDG-PET scans were obtained in 18 patients. The maximum standardised uptake value $\left(\mathrm{SUV}_{\max }\right)$ among all hypermetabolic lesions, the average SUV $\left(\mathrm{SUV}_{\mathrm{ave}}\right)$ of those lesions and the sum of total lesion glycolysis (TLG) of each hypermetabolic were evaluated. Higher $\mathrm{SUV}_{\text {ave }}$ $\geqslant 3.8$ was associated with considerably poorer OS following pazopanib treatment (median OS 10.8 months $v s$ not reached in patients with $\mathrm{SUV}_{\text {ave }}<3.8, P=0.039$, Figure $\left.3 \mathrm{D}\right)$. However, $\mathrm{SUV}_{\max }$ and TLG did not show significant association with treatment response.

\section{DISCUSSION}

This phase II pazopanib study demonstrated a PR rate of $18.9 \%$ (7 of the 37, 95\% CI 8.0-35.2) and a disease-control rate of $75.7 \%$ (28 of the $37,95 \%$ CI, 58.8-88.2) in metastatic GEP NETs. This study is the first one to assess the antitumour activity and safety

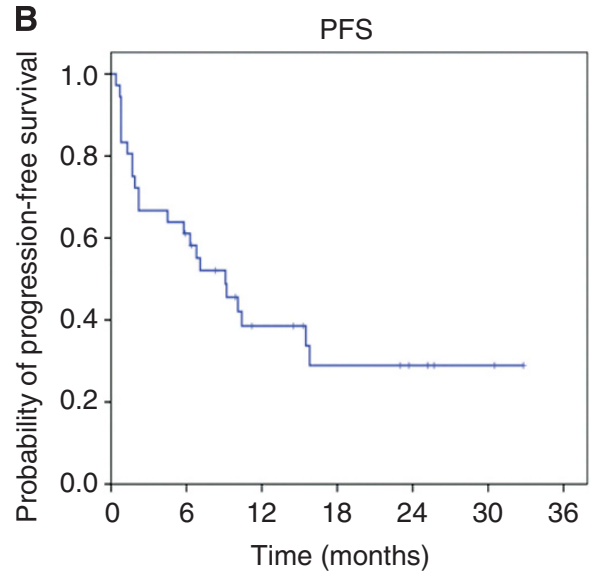

Table 3. Overview of adverse events

Number of patients (\%) Total $n=37$

Summary of adverse events (AE)

\begin{tabular}{|l|c|}
\hline All-grade AE & $36(97 \%)$ \\
Grade 3,4 AE & $15(41 \%)$ \\
AEs leading to treatment discontinuation & $4(11 \%)$ \\
AEs leading to death on treatment & $0(0 \%)$
\end{tabular}

Toxicity profile

\begin{tabular}{|c|c|c|}
\hline & \multicolumn{2}{|c|}{ Number of patients (\%) } \\
\hline & All grades & Grade $3 / 4$ \\
\hline \multicolumn{3}{|l|}{ Haematologic } \\
\hline Anaemia & $3(8)$ & $1(3)$ \\
\hline Neutropenia & $9(24)$ & $3(8)$ \\
\hline Thrombocytopenia & $4(11)$ & $1(3)$ \\
\hline \multicolumn{3}{|l|}{ Non-haematologic } \\
\hline Hypertension & $12(32)$ & $2(5)$ \\
\hline Proteinuria & $11(30)$ & $4(11)$ \\
\hline Skin rash & $12(32)$ & $0(0)$ \\
\hline Hand-foot syndrome & $20(54)$ & $1(3)$ \\
\hline Diarrhoea & $18(49)$ & $2(5)$ \\
\hline Anorexia & $17(46)$ & $2(5)$ \\
\hline Mucositis & $15(41)$ & $0(0)$ \\
\hline Alopecia & $7(19)$ & $0(0)$ \\
\hline Fatigue & $8(22)$ & $1(3)$ \\
\hline Nausea & $18(49)$ & $0(0)$ \\
\hline Pruritus & $4(11)$ & $0(0)$ \\
\hline Abdominal pain & $19(51)$ & $2(5)$ \\
\hline AST/ALT elevation & $6(16)$ & $2(5)$ \\
\hline Hyperglycaemia & $3(8)$ & $1(3)$ \\
\hline Hypokalemia & $1(3)$ & $1(3)$ \\
\hline
\end{tabular}

profile of pazopanib in metastatic GEP patients including NETs arising from nonpancreatic GI tract. Currently, the only available data on the efficacy of molecular targeted agents focus on G1 and G2 tumour pancreatic NETs.

The modest overall response rate of $18.9 \%$ and high diseasecontrol rate of $75.7 \%$ concur with the recently reported response patterns of everolimus (Yao et al, 2011b) and sunitinib for pancreatic NETs (Raymond et al, 2011). Everolimus monotherapy (10 mg daily) was compared with the best supportive care alone in 


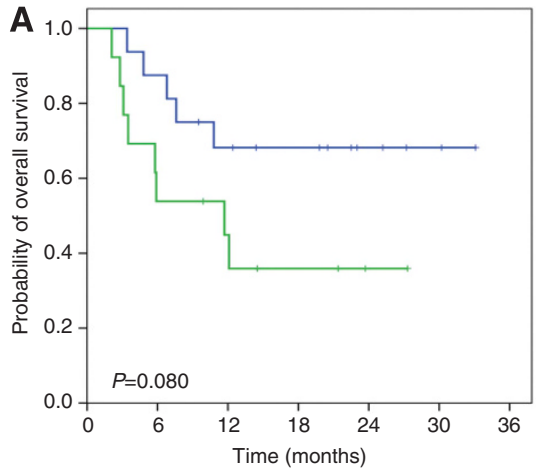

ㄱ $\mathrm{CgA} \leqslant 110(n=16)$ : median OS not reached $\sim \mathrm{CgA}>110(n=13)$ : median OS 11.7 months

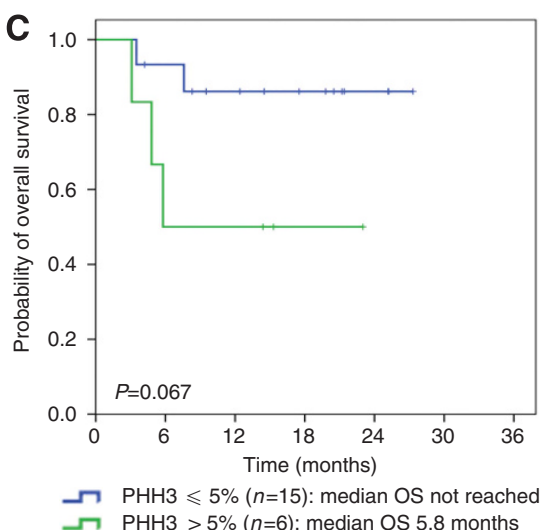

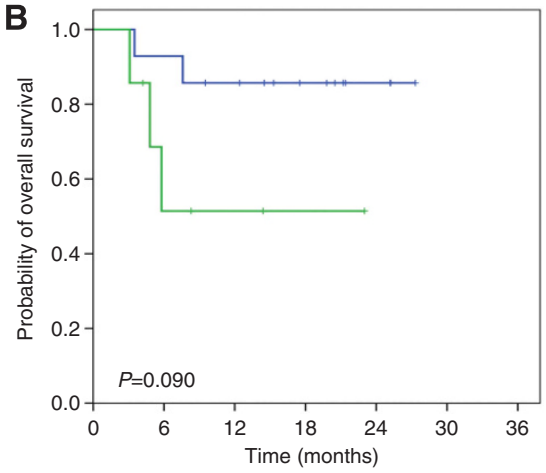

Ki-67 index $\leqslant 20 \%(n=14)$ : median OS not reached $\neg \mathrm{Ki}-67$ index $>20 \%(n=7)$ : median OS not reached

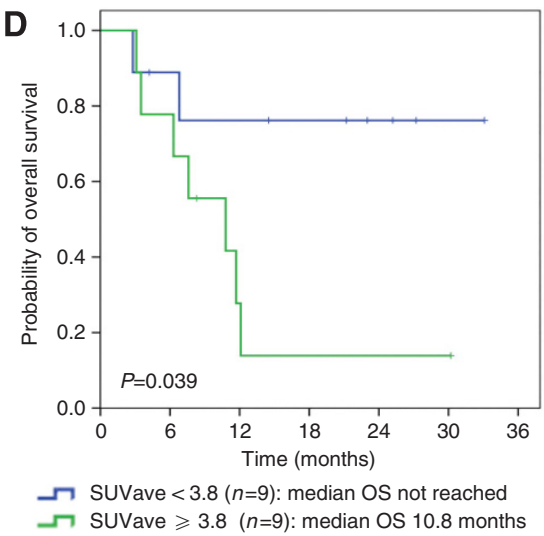

Figure 3. Overall survival according to biomarkers. (A) Overall survival according to serum chromogranin level ( $n=29)$. (B) Overall survival according to Ki-67 expression $(n=21)$. (C) Overall survival according to PHH3 expression $(n=21)$. (D) Overall survival according to SUV ave of all hypermetabolic lesions $(n=18)$.

the placebo-controlled RADIANT-3 trial of 410 patients with advanced progressing pancreatic NET (Yao et al, 2011b). Everolimus was associated with a significant prolongation in the median PFS (11.0 vs 4.6 months, HR for progression $0.35,95 \%$ CI $0.27-0.45)$. However, the confirmed objective PR was attained only in $5 \%$ and stable disease in $73 \%$ for everolimus treatment (Yao et al, 2008a). Another phase III trial that compared sunitinib with placebo in pancreatic neuroendocrine tumours demonstrated a low response rate of $9.3 \%$ (95\% CI, 3.2-15.4) and stable disease in $63 \%$ of sunitinib-treated patients (Raymond et al, 2011). The objectiveconfirmed response rate in this study $(18.9 \%)$ is substantially higher than those reported in the two trials (5-9.3\%). One of the plausible explanations for higher response rate achieved with pazopanib would be high number of patients with colorectal NETs, with only one-third of the enrolled patients suffering from pancreatic NET $(n=12)$ (Raymond et al, 2011; Yao et al, 2011b). The median PFS (15.5 months) observed in patients with pancreatic NETs treated with pazopanib $(n=12)$ was comparable to those reported in trials with sunitinib, everolimus and the combination of bevacizumab and temozolomide (median PFS, 11.4, 11 and 14.3 months, respectively). (Raymond et al, 2011; Yao et al, 2011b; Chan et al, 2012). Of note, we included G3 NET patients who have failed to previous cytotoxic chemotherapy. In G3 NETs, the response rate to pazopanib was $23 \%$. Nevertheless, patients with G3 GEP NETs did not show a durable response to pazopanib, with a median PFS of 5.8 months. On the basis of our results, pazopanib may be considered as a treatment option for selected G3 NET patients with limited treatment choices after failing to undergo cytotoxic chemotherapy.

Monitoring of serum CgA during treatment was correlated with tumour response and survival, with various tumour subtypes and treatments such as patients with functional carcinoid tumour following cytoreductive surgery (Jensen et al, 2007), low or intermediate grade neuroendocrine carcinoma treated with temozolomide and thalidomide (Kulke et al, 2006), and pancreatic NETs treated with everolimus (Yao et al, 2010; Yao et al, 2011a). In our study, low baseline CgA level was associated with longer OS and better responses to pazopanib. Follow-up CgA levels were available in only a fraction of patients - therefore, was not analysed in this paper. In addition, we tested the mitotic index measured with PHH3 IHC for the first time in NET. In this study, we found a good correlation between PHH3 and Ki-67 index, although Ki-67 index was the most significant predictive factor for survival in GEP NETs.

In conclusion, pazopanib showed a comparable efficacy to other targeted agents not only in pancreatic NETs but also in NETs originating from GI tract. In selected G3 patients, pazopanib may be considered as a treatment option in salvage setting. Genomic profiling to identify signal that predicts response to pazopanib in GEP NETs is currently ongoing.

\section{ACKNOWLEDGEMENTS}

GlaxoSmithKline provided the study drug.

\section{DISCLAIMER}

This was an investigator-sponsored trial and the company was not involved in study design or manuscript writing. 


\section{REFERENCES}

Chan JA, Stuart K, Earle CC, Clark JW, Bhargava P, Miksad R, Blaszkowsky L, Enzinger PC, Meyerhardt JA, Zheng H, Fuchs CS, Kulke MH (2012) Prospective study of bevacizumab plus temozolomide in patients with advanced neuroendocrine tumors. J Clin Oncol 30: 2963-2968.

Hamberg P, Verweij J, Sleijfer S (2010) (Pre-)clinical pharmacology and activity of pazopanib, a novel multikinase angiogenesis inhibitor. Oncologist 15: 539-547.

Hauso O, Gustafsson BI, Kidd M, Waldum HL, Drozdov I, Chan AK, Modlin IM (2008) Neuroendocrine tumor epidemiology: contrasting Norway and North America. Cancer 113: 2655-2664.

Hemminki K, Li X (2001) Incidence trends and risk factors of carcinoid tumors: a nationwide epidemiologic study from Sweden. Cancer 92 2204-2210.

Hurwitz HI, Dowlati A, Saini S, Savage S, Suttle AB, Gibson DM, Hodge JP, Merkle EM, Pandite L (2009) Phase I trial of pazopanib in patients with advanced cancer. Clin Cancer Res 15: 4220-4227.

Jensen EH, Kvols L, McLoughlin JM, Lewis JM, Alvarado MD, Yeatman T, Malafa M, Shibata D (2007) Biomarkers predict outcomes following cytoreductive surgery for hepatic metastases from functional carcinoid tumors. Ann Surg Oncol 14: 780-785.

Klimstra DS, Modlin IR, Adsay NV, Chetty R, Deshpande V, Gonen M, Jensen RT, Kidd M, Kulke MH, Lloyd RV, Moran C, Moss SF, Oberg K, O’Toole D, Rindi G, Robert ME, Suster S, Tang LH, Tzen CY, Washington MK, Wiedenmann B, Yao J (2010) Pathology reporting of neuroendocrine tumors: application of the Delphic consensus process to the development of a minimum pathology data set. Am J Surg Pathol 34: 300-313.

Kulke MH, Stuart K, Enzinger PC, Ryan DP, Clark JW, Muzikansky A, Vincitore M, Michelini A, Fuchs CS (2006) Phase II study of temozolomide and thalidomide in patients with metastatic neuroendocrine tumors. J Clin Oncol 24: 401-406.

Kumar R, Crouthamel MC, Rominger DH, Gontarek RR, Tummino PJ, Levin RA, King AG (2009) Myelosuppression and kinase selectivity of multikinase angiogenesis inhibitors. Br J Cancer 101: 1717-1723.

Lepage C, Rachet B, Coleman MP (2007) Survival from malignant digestive endocrine tumours in England and Wales: a population-based study. Gastroenterology 132: 899-904.

Lim T, Lee J, Kim JJ, Lee JK, Lee KT, Kim YH, Kim KW, Kim S, Sohn TS, Choi DW, Choi SH, Chun HK, Lee WY, Kim KM, Jang KT, Park YS (2011) Gastroenteropancreatic neuroendocrine tumors: incidence and treatment outcome in a single institution in Korea. Asia Pac J Clin Oncol 7: 293-299.

Modlin IM, Lye KD, Kidd M (2003) A 5-decade analysis of 13,715 carcinoid tumors. Cancer 97: 934-959.
Naraev BG, Strosberg JR, Halfdanarson TR (2012) Current status and perspectives of targeted therapy in well-differentiated neuroendocrine tumors. Oncology 83: 117-127.

Phan A, Yao JC, Fogelman DR et al. (2010) A prospective, multi-institutional phase II study of GW786034 (pazopanib) and depot octreotide (sandostatin LAR) in advanced low-grade neuroendocrine carcinoma (LGNEC). J Clin Oncol 28 (suppl): 15s(abstr 4001).

Raymond E, Dahan L, Raoul JL, Bang YJ, Borbath I, Lombard-Bohas C, Valle J, Metrakos P, Smith D, Vinik A, Chen JS, Horsch D, Hammel P, Wiedenmann B, Van Cutsem E, Patyna S, Lu DR, Blanckmeister C, Chao R, Ruszniewski P (2011) Sunitinib malate for the treatment of pancreatic neuroendocrine tumors. N Engl J Med 364: 501-513.

Terris B, Scoazec JY, Rubbia L, Bregeaud L, Pepper MS, Ruszniewski P, Belghiti J, Flejou J, Degott C (1998) Expression of vascular endothelial growth factor in digestive neuroendocrine tumours. Histopathology 32: $133-138$.

Yao JC, Hassan M, Phan A, Dagohoy C, Leary C, Mares JE, Abdalla EK, Fleming JB, Vauthey JN, Rashid A, Evans DB (2008a) One hundred years after 'carcinoid': epidemiology of and prognostic factors for neuroendocrine tumors in 35,825 cases in the United States. J Clin Oncol 26: 3063-3072.

Yao JC, Lombard-Bohas C, Baudin E, Kvols LK, Rougier P, Ruszniewski P, Hoosen St S, Peter J, Haas T, Lebwohl D, Van Cutsem E, Kulke MH, Hobday TJ, O’Dorisio TM, Shah MH, Cadiot G, Luppi G, Posey JA, Wiedenmann B (2010) Daily oral everolimus activity in patients with metastatic pancreatic neuroendocrine tumors after failure of cytotoxic chemotherapy: a phase II trial. J Clin Oncol 28: 69-76.

Yao JC, Pavel M, Phan AT, Kulke MH, Hoosen St S, Peter J, Cherfi A, Oberg KE (2011a) Chromogranin A and neuron-specific enolase as prognostic markers in patients with advanced pNET treated with everolimus. J Clin Endocrinol Metab 96: 3741-3749.

Yao JC, Phan A, Hoff PM, Chen HX, Charnsangavej C, Yeung SC, Hess K, Ng C, Abbruzzese JL, Ajani JA (2008b) Targeting vascular endothelial growth factor in advanced carcinoid tumor: a random assignment phase II study of depot octreotide with bevacizumab and pegylated interferon alpha-2b. J Clin Oncol 26: 1316-1323.

Yao JC, Shah MH, Ito T, Bohas CL, Wolin EM, Van Cutsem E, Hobday TJ, Okusaka T, Capdevila J, de Vries EG, Tomassetti P, Pavel ME, Hoosen S, Haas T, Lincy J, Lebwohl D, Oberg K (2011b) Everolimus for advanced pancreatic neuroendocrine tumors. N Engl J Med 364: 514-523.

This work is published under the standard license to publish agreement. After 12 months the work will become freely available and the license terms will switch to a Creative Commons AttributionNonCommercial-Share Alike 3.0 Unported License. 